How to Cite

Estevez, A. G., Espinosa, A. H. R., Rodríguez, D. L., \& Leyva, T. F. (2019). Current approaches and controversies: legalization and non-legalization of drugs. International Journal of Health \& Medical Sciences, 2(1), 26-32.

https://doi.org/10.31295/ijhms.v2n1.85

\title{
Current Approaches and Controversies: Legalization and Non- Legalization of Drugs
}

\author{
Ailén Galano Estevez \\ Universidad de Oriente, Santiago, Cuba \\ Corresponding author email: ailen.galanoestevez@gmail.com \\ Ana Hortensia Rodríguez Espinosa \\ Villa Colibrí Therapeutic Community, Santiago, Cuba \\ Email: a.hortensia@nauta.cu \\ Dilka Leyva Rodríguez \\ Universidad de Oriente, Santiago, Cuba \\ Email: talimar81@gmail.com \\ Thalia Fuentes Leyva \\ Universidad Técnica de Manabí, Portoviejo, Ecuador \\ Email: fuentesthalia123@gmail.com
}

\begin{abstract}
When a critical analysis to date has made of, the historical aspects related to the topic of drugs, we could distinguish the existence of contrary positions regarding the possibility of legalizing them or not legalizing them. This dilemma is a very topical and important issue since opting for one position or another has economic, political and social implications that are necessary to keep track of. Therefore, the present study aims to; evaluate the advantages and disadvantages that would imply the legalization and non-legalization of drugs. Scientific journals from five years ago have consulted to date, theses and dissertations on the subject, digital and printed books that appear in libraries. Personal communication has made with researchers in the area of addictions. The main results were that the legalization of drugs is very dangerous for society due to its highly addictive and harmful effects on human beings. Likewise, specialists in addictions affirm that legalization can send the wrong message that consuming marijuana and other illegal drugs does not represent risks, which in turn can generate the wrong perception of safety and promote the promotion of consumption. In conclusion, the legalization would not mean the disappearance of the current drug lords, since prices would fall, but this would have compensated with a higher demand, which would increase the sales-consumption volume.
\end{abstract}

Keywords---drugs, illegalization, legalization.

\section{Introduction}

The consumption of drugs is as old as man's own emergence and development since he has used substances from ancestral times that allow him to modify the perception of his reality and achieve a state of supposed "well-being". In this way, its use has been changing throughout history, for example, opium from China went from has ingested mainly as medicine to being smoked for pleasure (Gómez, 2012; Markolinda \& Sawirman, 2018). Currently, the use of drugs is not only associated with healing purposes, magical religious like in its infancy, but with the intention of experiencing new sensations, achieve ecstasy, fullness, and other aspects that have been promoted from some ideological movements (for example the Hippie movement).

ISSN 2632-9433

Received Jan 20, 2019 / Accepted Jun 18, 2019 / Published Jul 05, 2019 
When a critical analysis to date has made of, the historical aspects related to the topic of drugs, we could distinguish the existence of contrary positions regarding the possibility of legalizing or not legalizing drugs. This debate isn't unknown, it has simply been renewed, recycling old arguments, and combining them with some new ones (Gómez, 2012). Even so, this dilemma is a very topical and important issue since choosing one position or another has economic, political and social implications that must have kept in mind.

The discussion about this problem in the current world is increasingly wider, which is why it has considered necessary to carry out an updated thematic review with the following objective: to evaluate the advantages and disadvantages that legalization and non-legalization of drugs would imply. To achieve this end, positions must be determined on the subject that is defended by different authors nowadays and the arguments proposed by them.

During the analysis, we take into account how the debate is currently taking place in the world and special attention has given to its manifestation in our country, Cuba. Its analysis will be based on some questions that are intended to be answered in the article itself but whose maximum intention is to awaken in the reader curious about the subject and the possibility of making an analysis. That serves as a support to defend one or another position, since that it is impossible that we can avoid a debate like the one that happens around drugs and their control in our days.

\section{Material and Methods}

Research methods used to locate the relevant studies; A review of the bibliographic databases where the issue of legalization and non-legalization of drugs was made, taking into account the references of all relevant publications on the subject for ten years to the present, and documents written in Spanish and English. They were consulted scientific journals from five years ago to date, theses and dissertations on the subject, digital and printed books that appear in libraries. Personal communication has made with researchers in the area of addictions, especially to ensure that important published works or unpublished communications have not omitted.

\section{Analysis of documents}

The analysis of documents is the process by which the most outstanding information contained in a given information source is determined and extracted, which is separated into its constituent elements based on a specific organization. The analysis carried out involved in the following phases.

a) Familiarization with the content of the document or series of documents.

b) Preliminary classification of documents based on their content and organizational criteria (first evaluation).

c) Selection and extraction of the most relevant or outstanding information, in order to eliminate all that is not necessary, and thus reduce the volume of materials to be handled.

d) Verification of the concepts or data in individual extracts (second evaluation).

\section{Synthesis of the information}

It is the process of condensation and distillation of the information analyzed from one or more sources, which has now presented in a new format or structure and with an interpretative or evaluative point of view.

The synthesis consisted of the following phases:

a) Ordering and combination of information.

b) Comparative evaluation of the different extracts or data (third evaluation).

c) Condensation of the information in a structure and more affordable way and in accordance with the objectives and sources worked.

\section{Results and Discussion}

The legalization of drugs implies that the laws that prohibit the possession, consumption, supply, and production of drugs in the world have modified. The authors who defend this position consider that the illegalization of drugs is not solving the problems that drug use generates in public health and is fomenting other equally serious contradictions. Such as the drug trafficking developed by the mafia, the adulteration of illicit substances and the disjunctive that 
supposes the existence of illegal drugs (marijuana, cocaine, heroin, etc.), and other legal ones (tobacco and alcohol), when the repeated consumption of all of them can cause addiction or dependence.

Another interesting aspect to declare regarding the debate on the legalization of drugs is related to the statement made by (Babín, 2013), when he states that "legalizing is not the same as decriminalizing, it is not the same to decriminalize consumption as trafficking and It is not the same to decriminalize private consumption as the public. In this regard, the author points out that it is not the same to recognize the existence of the addictive disease and to proceed accordingly, to accept that the production, collection, distribution, and sale of drugs, go on to constitute a free market, sponsored by governments or "companies "Authorized for it.

Regarding this situation, in 2010, Felipe González ${ }^{1}$ defended the "elimination of the prohibition of drugs" as the best solution to fight against drug trafficking and the violence that this implies. These words led to a controversy, since José Antonio Alonso, the socialist parliamentary spokesperson, did not agree with the idea of legalizing drugs, while stating that this proposal had not been effective in other countries, where drugs are legal and however, the Mafia continues to exist and the health problems in the population have not improved.

Likewise, more recently, Almudena Grandes ${ }^{2}$ opined that the only way in which Mexican cartels can reduce their power is to legalize narcotics so that the Mexican State can control its distribution and consumption to overcome clandestinely (Trujillo, 2014). The Spanish writer clarified that although she believes that drugs are harmful to health, if the Mexican State assumed control and administered their sale, the effect would be to dismantle criminal organizations and thus end violence, as the ability to seduce of narcotic drugs would be reduced at all levels.

In this way, the writer specified that this task cannot be promoted only in Mexico since only one country does not have the capacity to implement this perspective, because the problem of drug trafficking would move to neighboring countries. As can be seen, the authors who defend the perspective of legalizing drugs start from the foundation that once drug trafficking is legalized, illegal drug trafficking ceases to exist and, with it, the violence associated with it (Hernández, 2008).

Certainly, we could ask ourselves so far, would the drug legalization eradicate the problems of drug trafficking, political and police corruption and the violence that this implies? Although the defenders of this first alternative consider that these aspects would has solved by means of systems that imply from the "total legalization" 3 to various forms of "regulated legalization"4, it is considered that the regulation of drugs worldwide will not be able to prevent the illegal formulas (mafias) from disappearing. In the first place, all-important legal business originates a black market (oil, weapons, works of art, precious metals, tobacco, etc.). In addition, for the mafia, the drug is not their only business; these cartels are at the base of human trafficking networks, in the illegal trade of minerals and precious stones, in the arms trade, among others (Babín, 2013).

There are examples that show that the legalization of drugs does not mean that drug trafficking has done away with, as is the case of tobacco where its legality does not stop a burgeoning contraband from continuing to exist. The Netherlands has had its own problems with the growing use of cannabis products. From 1984 to 1996, the Dutch released the use of cannabis, however polls show that the prevalence of cannabis in this country increased more strongly during those years. For the age group 18-20 years, the increase went from 15 percent in 1984 to 44 percent in 1996.

Similarly, Switzerland, with some of the most liberal drug policies in Europe, experienced something similar with what it has come known as "Needle Park". The Aguja Park became a stage for drug addicts from all over Europe. It was in area to which addicts could go to openly buy drugs and inject heroin without intervention or control by the police. The rapid decline of the neighborhood that surrounded the Aguja Park, with increasing crimes and violence, led to the authorities finally having to close it in 1992 (Gómez, 2012).

As for the possibility of eradicating violence and corruption through the legalization of drugs, those who make this approach seem unaware of the effects of drugs on man and society in general and therefore wrongly assume this position. There are dissimilar investigations that have shown that although there is a type of violence associated with the illegality of the drug market, and generally exercised by traffickers, there is also another associated with drug use itself.

${ }^{1} \underline{\text { Politico }} \underline{\text { Spanish}}$, general secretary of the Spanish Socialist Workers Party (PSOE) from $\underline{1974}$ to $\underline{1997}$ and third president of the Government since the restoration of democracy in Spain, from 1982 to 1996.

2 Almudena Grandes is a writer Spanish.He is a regular columnist for the newspaper El País and a member of the Cadena SER programs. It has always been meaning for their political positions of the left, having shown their public support for the United Left, as well as other social movements.

${ }^{3}$ It would eliminate all forms of government control.

${ }^{4}$ The drugs would be legally available under a government control system which implies age limitations, restrictions on the quantity purchased in a time and prohibition of sale to drunken persons. 
It is evident that the use of drugs endangers not only the consumer but also those around him; say the family as the primary group in which the individual develops. A qualitative study conducted in 2010 by UNODC in four cities in Pakistan to examine the social and economic effects of drug abuse in the family indicated that the wives of drug addicts suffered serious economic, physical and psychological consequences.

In the case of cocaine consumption data in France, for example, it has shown that this drug has as characteristics a disinhibition in behaviors, which can lead to sexual aggressions, acts of violence, compulsive behaviors, among others. In the case of crack, its regular use can cause hallucinations, violent behavior, paranoid or suicidal. There is research that shows that the rates of committed and attempted suicides among users of illegal drugs are much higher than of the general population (Hernández, 2008).

There is no doubt that the legalization of drugs is very dangerous for society due to its highly addictive and harmful effects on human beings. Likewise, specialists in addictions affirm that legalization can send the wrong message that consuming marijuana and other illegal drugs does not represent risks, which in turn can generate the wrong perception of security and promote the promotion of consumption (Cachanosky, 2010).

If we continue with the arguments raised by the proponents of the proposal to legalize drugs, we can identify that there is a basis for legalization in a regulated manner. In this way, drugs would be legally available under a government control system that would imply restrictions on advertising, age limitations, restrictions on the amount purchased at a time, requirements on the way in which certain drugs should be supplied, prohibition of sale to drunk people, among other aspects.

Regarding this issue, we could ask ourselves, if drugs have legalized only for adults, how has an illegal market for minors prevented? Definitely, it is considered that drug trafficking would concentrate on said young people in order to settle the losses that can be generated by another sector. Furthermore, it cannot be forgotten that young people are precisely one of the groups that report the highest consumption rate, so the problem of illegal consumption and drug trafficking would not be solved with this measure.

Another of the approaches made by the defenders of the legalization of drugs has related to the issue of ethics. In this regard, they consider that while drugs cause harm to operate, this does not mean that ethically the act is wrong. That is, if a person prefers to have a shorter life but enjoy the use of the drug, while not damaging the rights of third parties, it is in its full right and freedom to do so. It is the decision of the individual to want to lead a healthy and long life or one with vices but shorter (Cachanosky, 2010).

Regarding this approach to ethics, it has considered that if what has defended is the freedom to choose, whether for minors or for adults, it must be remembered that the drug addict loses that freedom and becomes a slave to drugs (Solanet, 2011). These approaches perhaps mean accepting that it is ethical to profit from drug addiction, as long as the State intervenes to regulate them. From this position then ethics would involve letting others fall ill and not having the possibility of helping them, of properly integrating them into society so that they participate in it as protagonists of the story and not as mere observers who insert themselves in bubbles to evade their reality.

From what ethical position is someone going to want to legalize products that harm people? What is the point of allowing a law that will generate more consumption of those drugs that harm us? These are the questions and arguments, among others, that they wield those that hold in the position that drugs must remain prohibited by law (Cachanosky, 2010).

Those who defend the full legalization of drugs based on the freedom to choose what each person should have, also argue that the opposite of freedom is responsibility. By this, they mean that if drugs are legalized in a free society you cannot expect afterward that the addicts will be kept by taxes since it was their decision to lead a life that in the long term would harm them.

This approach advocates an indifferent society that admits the possibility of seeing a good part of its members has legally destroyed, and little by little, it will lose its way until it disappears. It seems terrible that there are people who can consider doing nothing to help addicted people who are sick, and simply have the simple perception that they are free to choose that way of life.

Moving on to another element, if full legalization were made that would completely eliminate all forms of government control, from the legislative point of view, in the case of accidents caused by people who have used drugs, what legal responsibility to the State and the professionals involved in the distribution?. How have prevented? How do you prevent syringes from have shared? Which agency would enforce the law? What penalties and penalties would have established for the violations, and how the risks of corruption and 'illicit trafficking' would have treated? These are of the questions that can have raised, but there may be many others could question the perspective of legalizing drugs.

In the article entitled, legalization or criminalization of the drug. de (Solanet, 2011), the author proposes a series of approaches that seem significant to rescue due to the possibility that they offer us to assess whether the legalization of drugs could really be an effective alternative. The author makes us think about whether advertising 
such as the one that exists for alcoholic beverages and cigarettes will have developed for the drug, and in that case. Whether it will be enough for that advertising to say that its consumption is bad for health or will have that to say that the consumption creates addiction, is destructive and can cause behaviors that affect third parties. If you had to include this last message that recognizes that health and life are at stake, how would you explain that the state allows its free sale?

The arguments put forward by defenders of legalization, although well intentioned, may seem logical and simple when they are not; they do not support critical evaluation and tend to go against the general experience (Gómez, 2012). Legalize the production and marketing of all drugs without having made an exhausted assessment of the benefits and costs and of this choice, may imply bad consequences for public health, so it is necessary to continue carrying out studies that allow greater clarity of the effectiveness or otherwise of said alternative.

It is also necessary a reflection on the real causes. That is at the base of the consumption of drugs, either by personal conflicts, family, hedonistic culture, the search for acceptance in a group of friends, or many others that could explain these behaviors addictive and that must be not only diagnosed but must be prevented and intervened through community and social programs that enable their care and treatment. Thus, also feed the efforts and local and national strategies for the prevention of addictions, harm reduction, and treatment (Barra, 2010).

Although up to now we have referred to how the current debate on the legalization of drugs in the world is taking place, we consider it necessary to specify the position assumed by the voices that have heard in Cuba. In this regard, in a 2011 article on the legalization of marijuana, it has stated that Cuba believes that decriminalizing marijuana would be a "historical irresponsibility" that could lead to "irreparable damage".

Israel Ibarra secretary of the National Drug Commission of the island considers in November 2014 that legalizing the narcotic would cause great problems for the two nations. The proposal of a group of congressional representatives to legalize marijuana in the United States is irrational and can bring great problems to that country and Cuba, Cuban experts say today. "It would not be rational to try to decriminalize the use of marijuana it would be historical irresponsibility "that" would bring great problems to the North American society and to Cuba, "the secretary of the National Commission of Drugs (CND), Israel Ibarra, told reporters in this year of 2014.

If this was done,"the damage would be irreparable", considered Ibarra, after stressing that this proposal "violates the UN Convention on Narcotic Drugs of 1961", which limited the use of these substances for medical and scientific purposes and laid the foundations for a solid cooperation in the fight against international drug trafficking (Rocha, 2010). On the other hand, the psychiatrist Carmen Borrego, head of the Section of Mental Health and Substance Abuse of the Ministry of Health, stressed. The damage to human health, caused by marijuana, "is duly demonstrated", and that "it is also a drug that opens the way to the consumption of others (Camacho, 2011).

\section{Arguments in favor of the legalization of drugs}

a) One of the central arguments for the legalization of drugs is based on the fundamental right that each person has the right to choose how he wants to lead his life, which includes the obligation of the state to respect the decision of the citizen on the substances he decides to use

b) Other supporters of this measure base their defense on the belief that it would be an important means to eradicate mafias related With drug trafficking, legalization would end the alliance of drug trafficking and political power, and

c) legalization would reduce the price of drugs, so much s people who are addicted to drugs would not have to steal or prostitute themselves to pay for the high prices that these substances currently have.

d) Legalizing the drugs would make the manufacture of these substances are within the scope of the regulations of a legal market. Under the prohibition, there are no quality controls or sale of standardized doses. This has led to high levels of mortality from overdose or poisoning from drug use.

e) Governments no longer have to spend billions of dollars in the fight against drugs, these resources being used to fight the real criminals (murderers, terrorists, thieves, etc.).

f) The legalization would lead to society to learn to live with drugs as it has done with other substances such as alcohol and snuff.

\section{Arguments against the legalization of drugs}

a) People who are against the legalization of drugs pose that what is really needed is a deep and sustained social transformation that alleviates the needs, injustices and tensions that are often nourished by the drug crises and a change in the way that those who want to consume them perceive them. 
b) The legalization would not mean the disappearance of the current drug lords since they would lower prices, but this would have compensated with a higher demand, which would increase the sales-consumption volume.

c) There are still many questions that demonstrate the lack of clarity presented by the proposal to legalize drugs; since it is not legitimate what drugs would be legalized, if they would only be legal for the elderly, in this case how it would prevent an illegal market for minors, what would happen to those who want to ingest more doses of the established, among other questions that make us reflect on the effectiveness of the proposal.

\section{Conclusion}

It has demonstrated with current examples that the legalization of drugs would increase consumption. It does not really favor the recovery and reintegration of the drug addict; the traffic would not disappear, the mafias would continue to exist; allows the self-destruction of the individual; cheapening would not eradicate crime, and the action of the State would have delegitimized by allowing the sale of toxic products with secondary effects.

\section{References}

Babín, F. (2013). The debate over the legalization of drugs. Barra, A. After the lost war, what? The debate on the legalization of drugs in Mexico. ISBN: 978-607-7833-12-3. . VOL. 25 NUM. 1 (p.7-9). Mexico. (2010).

Cachanosky, I. (2018). An analysis about the legalization of drugs. Argentina. (2010). Extracted on November 8, from: http://www.escuelaaustriaca.org/esp/ponencias_esp_2010/cachanosky_ponencia.pdf

Camacho (2011). A. Anti-drug Policies in Colombia: Successes, failures and losses. Bogotá: Uniandes Editions.

Gómez, J. (2012). Eight myths of the legalization of drugs. Bogotá: IEMP Editions.

Hernández, A. (2008). Political and social impact of the legalization of drugs. Papers for reflection, Number XLIV.

Markolinda, Y., \& Sawirman, -. (2018). High risk of HIV towards sexual transaction, use of drugs, and lingual symbol of day-pay workers. International Journal of Health Sciences, 2(2), 68-77. https://doi.org/10.29332/ijhs.v2n2.161

Rocha, R. (2010). The New Dimensions of Drug Trafficking in Colombia. UNODC, Ministry of the Interior and Justice of the Republic of Colombia.

Solanet, M. (2011). Legalización or criminalization of the drug? Communication in private session of the National Academy of Moral and Political Sciences. ISSN: 0325-4763. Buenos Aires, Argentine Republic. Extracted on November 8, 2018 from: http://www.ancmyp.org.ar/user/files/09\%20Legalizaci\%C3\%B3n.pdf

Trujillo, A. (2014). Legalization of drugs, a solution to the Mexican crisis by drug trafficking. 


\section{Biography of Authors}

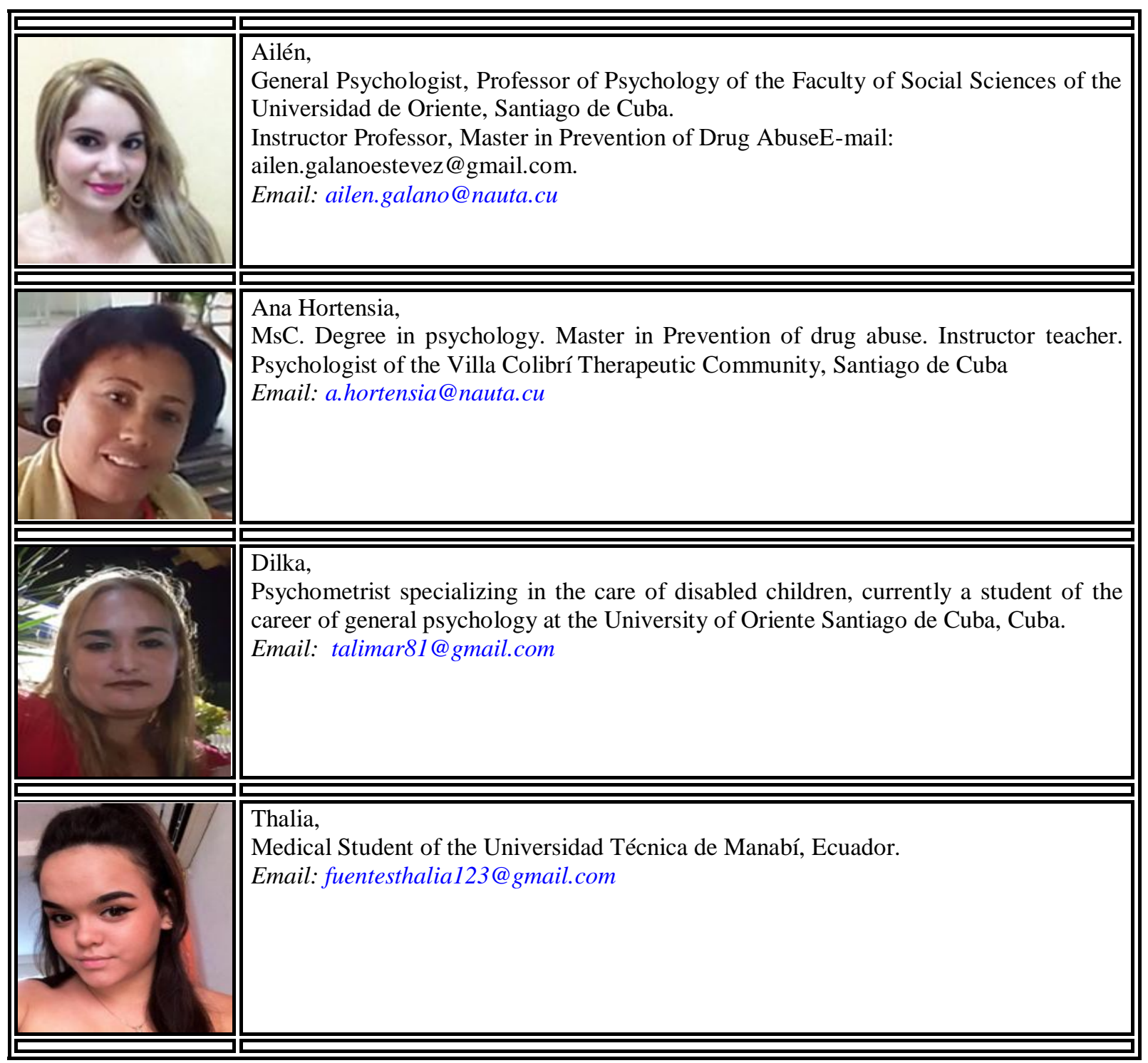

